\title{
Shhhhh! No laughing allowed.
}

Editor's note: The following bumorous pieces are from the April 1 issue of the University of Washington Libraries' Weekly Online News, written by Charles Chamberlin, Steve Eichner, Antony Hopkins, Elaine Jennerich, Susan Kemp, and Paula Walker. Reprinted with permission from the University of Washington Libraries.

\section{New staff travel funding source under review}

A novel plan for finding additional resources to ease the burden of travel expenses on libraries staff is under review by the libraries. The plan calls for utilizing the extradition policies that are in place between law enforcement agencies in most states. When requesting travel to a given city, a database of unsolved crimes in that jurisdiction will be consulted. If an extraditable offense is found, a staff member will anonymously submit evidence implicating themselves in the crime. After being escorted by friendly local police to the destination city, exonerating evidence will be forwarded by the libraries.

The plan does have some limitations, and work remains on many details, but it is hoped that it will provide at least some fiscal relief for staff. Additional benefits of the plan include expedited passage through airport security, and a higher level of personal protection while en route. The committee expects to have the full plan ready for presentation to the council by April 15 th.

\section{Signage task force hires design consultant}

The Libraries Signage Task Force has hired renowned consultant Martha Stewart to assist in creating the perfect atmosphere for learning and research in the entire UW Libraries system. Ms. Stewart will begin with Suzzallo Library as the prototype and each floor will receive what Martha refers to as "hues and tones that make you smarter!"

Each floor will receive signage in appropriate colors: Basement: Shrimp Bisque; Ground Floor: Baby's First Summer; First
Floor: Taupe Temptress; Second Floor: Cayenne; Third Floor: Coyote; Fourth Floor: Aubergine; Fifth Floor Conference Rooms: Bland Beige.

To add to the ambience, Martha has designed major destination signs for the 1 ibraries that will be in the shape of puffy cumulus clouds. "They're heavenly!" sighed Betsy Wilson, director of UW Libraries. Our corporate sponsor for this effort is K-Mart, whose logo will now appear on all signage.

\section{OneWednesday, 4/3/02}

Please join us for OneWednesday, April 3rd from 1:30-2:30 p.m. in the Tower Room. This month's topic will be "Early retirement: is 40 too early?" Early Retirement is one of the ideas that grew from recent brainstorming sessions on ways to save money and generate income. Here is a chance to put on your "creativity cap" and openly discuss your ideas about this intriguing concept.

\section{Manuscripts, Special Collections, University Archives acronym status resolved}

The Manuscripts, Special Collections, University Archives Division is pleased to announce that its acronym status has been resolved. In 1999, following the merger of the Special Collections and Preservation Division with the Manuscripts and University Archives Division, "MSCUA" was submitted to the University of Washington Harmonical Acronym Team.

The intent of having MSCUA officially elevated from abbreviation to acronym was to increase ease of use and foster a unique campus identity. It was initially anticipated that the approval process would be short. However, the team determined that there were several phonetic interpretations that they were required to investigate. "Muskawuh," "Emskwah" and "Skway" (the " $\mathrm{m}$ " is silent) were all reviewed and considered by the team.

After several lively meetings and a period of public comment, the team approved the divisions' preferred choice of "Muskawuh," and it has now been added to the listing of official university acronyms. 